\title{
PENENTUAN LOKASI TEMPAT EVAKUASI AKHIR PENGUNGSI PADA ANCAMAN BENCANA TSUNAMI KOTA PADANG
}

\author{
Rafiqa Fijra \\ Fakultas Teknik Universitas Gadjah Mada \\ Email: fijrarafiqa@gmail.com
}

\begin{abstract}
Padang is capital city of West Sumatera whose coastal layout and approximately 50\% of population live in low area. It opposites to the Indian Ocean which near the Megathrust subduction which can trigger a powerful earthquake and generate tsunami. Because of the potential risk, important to finding the final evacuated region (TEA) location addressed by evacuee of each affected village, and defining the evacuee population and its susceptive population on each TEA. Defining the location TEA is provided by formulating the linear programming model which minimizing the total traveled distance. Then, defining of population and susceptive of evacuee in each TEA also analyzed to support the response disaster occurred. The optimization model is conducted in three level scenarios of tsunami scale, that are big, medium, and small
\end{abstract}

Keywords: Linear programming; Megathrust; TEA; Tsunami disaster.

\begin{abstract}
ABSTRAK
Padang merupakan ibu kota provinsi Sumatera Barat yang memiliki tata ruang yang didominasi pada kawasan pesisir, dan sekitar $50 \%$ populasi penduduknya bertempat tinggal di area rendah. Kota Padang berbatasan dengan Samudera Hindia yang berada dekat dengan Subduksi Megathrust yang berpotensi menimbulkan gempa tektonik yang berpotensi tsunami. Berdasarkan potensi risiko yang dimunculkan, penting untuk menentukan lokasi Tempat Evakuasi Akhir (TEA) yang dituju oleh pengungsi yang berasal dari masing-masing kelurahan yang terkena bencana, serta mengetahui jumlah populasi pengungsi serta porsi kelompok rentan yang berada pada masing-masing TEA. Penentuan lokasi TEA dilakukan dengan formulasi model linear programming yang bertujuan untuk meminimasi total jarak tempuh pengungsi dalam melakukan pengungsian. Kemudian, penentuan jumlah populasi pengungsi dan porsi kelompok rentan pada masing-masing TEA dilakukan untuk mendukung tindakan pada tahap tanggap darurat setelah terjadi bencana. Model optimasi dilakukan untuk tiga skenario skala bencana tsunami, yaitu skala besar, skala menengah, dan skala rendah.
\end{abstract}

Kata Kunci: Bencana tsunami; Linear programming; Megathrust, TEA. 


\section{PENGANTAR}

Kota Padang merupakan Ibu Kota Provinsi Sumatera Barat, dengan luas area 1.414,96 km². Sebelah barat Kota Padang berbatasan dengan Samudra Hindia dan berada dekat dengan Lempeng Indo-Australia dan Lempeng Eurasia. Terdapat Subduksi Megathrust di bawah Kepulauan Mentawai. Subduksi ini berpeluang menimbulkan gempa tektonik yang berpotensi tsunami (McCloskey dkk, 2008). Tata ruang Kota Padang didominasi pada kawasan pesisir, pembangunan Kota Padang yang dominan pada kawasan pesisir dapat terlihat dari Gambar 1. Selain itu, Kota Padang memiliki topografi yang mana sejumlah daerahnya memiliki permukaan daratan yang rendah, dan sekitar $50 \%$ penduduk hidup di area rendah, yaitu sekitar 0-5 meter dari permukaan laut (Data BPS 2011 dalam Ashar dkk, 2014). Besarnya risiko pada ancaman bencana tsunami tersebut, Kota Padang memerlukan perencanaan yang matang dalam menghadapi potensi bencana tersebut. Pengurangan risiko bencana dilakukan dengan mengembangkan strategi yang efektif.

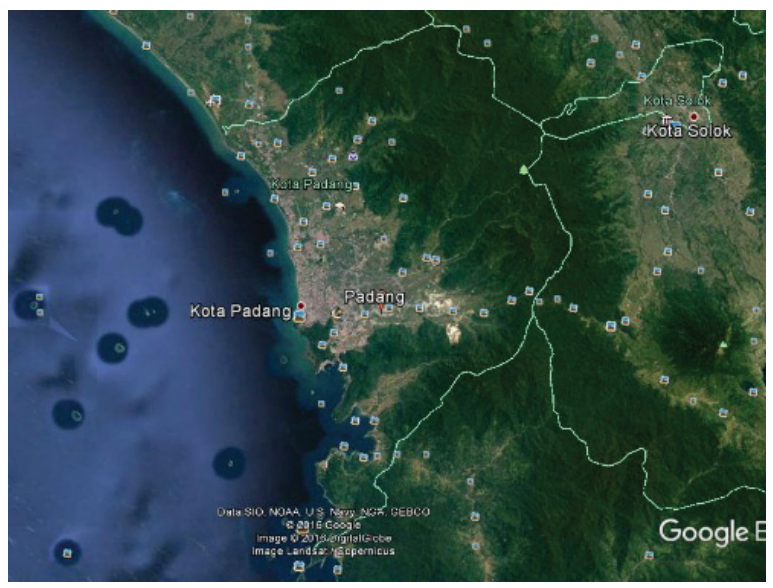

Gambar 1. Peta Kota Padang

(Sumber: www.googleearth.com, 2016)

Rencana kontingensi disusun oleh BPBD Kota Padang agar masyarakat di area rawan bencana dapat melakukan evakuasi dan segera mendapatkan pertolongan pascabencana. Setelah bencana tsunami mereda, masyarakat akan melakukan evakuasi menuju Tempat Evakuasi Akhir (TEA) yang telah ditentukan oleh BPBD Kota Padang untuk memperoleh bantuan yang akan berlangsung selama beberapa waktu selama mendapatkan tempat hunian yang lebih layak.

TEA merupakan lokasi akhir pengungsian yang pada dasarnya memiliki fungsi sebagai tempat berkumpul anggota keluarga pascabencana terjadi, dan tempat pengungsi mendapatkan bantuan dan melakukan aktivitas harian rumah tangga hingga proses pemulihan dimulai. Aktivitas yang berada pada TEA dilaksanakan kepada masyarakat yang kehilangan harta benda pascabencana tsunami terjadi (BNPB, 2014).

BPBD Kota Padang mengelompokkan populasi pengungsi ke dalam kelompok rentan dan kelompok nonrentan. Pembagian kelompok ini mempertimbangkan perbedaan tingkat prioritas populasi yang membutuhkan bantuan-bantuan pascabencana. Keberadaan populasi rentan memerlukan tingkat prioritas yang lebih tinggi dibandingkan populasi nonrentan pada suatu tempat evakuasi dalam memperoleh bantuan. BPBD Kota Padang menentukan kelompok rentan terdiri dari empat golongan berikut yaitu: pengungsi wanita, pengungsi dengan usia ketergantungan, penduduk kurang mampu, dan disabilitas.

Penelitian mengenai penentuan lokasi TEA telah dilakukan oleh Purbani $d k k$, (2014). Penelitian dilakukan untuk Kota Pariaman dengan menggunakan analisis jaringan (network analysis) melalui penerapan SIG (Sistem Informasi Geografis). Lokasi sejumlah TEA tersebut berada di wilayah aman bencana dan diperoleh jalur horizontal menuju TEA. Perumusan masalah yang dilakukan pada penelitian ini adalah menentukan lokasi Tempat Evakuasi Akhir (TEA) yang dituju oleh pengungsi yang berasal dari masingmasing kelurahan yang terkena bencana dengan menggunakan solusi optimal serta mengetahui jumlah populasi pengungsi serta porsi kelompok rentan yang berada pada masing-masing TEA. Penentuan lokasi Tempat Evakuasi Akhir (TEA) yang dituju oleh pengungsi yang berasal dari masing-masing kelurahan yang terkena bencana diperoleh 
dengan solusi optimal menggunakan Linear programming.

Linear programming (LP) merupakan teknik matematika untuk menemukan solusi optimal untuk suatu permasalahan yang mana fungsi tujuan dan constraint dinyatakan dalam bentuk linear (Chinnek, 2001). Suatu permasalahan dapat dimodelkan dengan LP jika seluruh fungsi, baik fungsi tujuannya maupun batasannya dapat dimodelkan dengan menggunakan persamaan (atau pertidaksamaan) linier. Mayoritas LP ini digunakan untuk menentukan keputusan terbaik (optimal) dengan mempertimbangkan keterbatasan sumber daya yang tersedia (Masruroh, 2014). Pada permasalahan ini memiliki constraint suatu varibel harus bernilai integer (diskrit), maka dinamakan integer programming.

Penelitian diawali dari informasi tingkat bahaya bencana tsunami di Kota Padang di setiap kelurahan. Tingkat bahaya tsunami diperoleh dari peta bahaya tsunami berdasarkan hasil kajian risiko bencana yang dilakukan BNPB yang terdapat pada Gambar 1 . Tingkat bahaya tsunami digolongkan menjadi tiga zona, yaitu tingkat bahaya tinggi (zona merah), sedang (zona kuning), dan rendah (zona hijau). Penelitian ini dibentuk tiga skenario skala bencana dengan memperkirakan area terkena bencana berdasarkan data tingkat bahaya kelurahan tersebut, sehingga skenario terbentuk sebagai berikut: pertama, Skenario skala bencana tinggi mengenai kelurahan yang berada di ketiga zona bahaya. Kedua, Skenario skala bencana sedang yang mengenai kelurahan di zona merah dan zona kuning, dan Ketiga, Skenario skala bencana rendah mengenai kelurahan di zona merah.

Setiap kelurahan memiliki data jumlah penduduk serta informasi porsi jumlah kelompok rentan perkelurahan. Data ini diperoleh dari hasil survei yang dilakukan oleh BPBD Kota Padang. Kemudian diperoleh data lokasi TEA yang berpotensi untuk digunakan beserta kapasitas daya tampung pengungsi yang dimiliki. Selain itu jarak antara setiap kelurahan menuju setiap TEA digunakan sebagai gambaran jarak yang akan ditempuh oleh pengungsi dari kelurahan yang terkena menuju tempat evakuasi, pada penelitian ini data diperoleh menggunakan aplikasi googleearth. Berdasarkan titik asal pengungsi pada area terkena bencana dan kapasitas lokasi TEA yang tersedia, maka perlu penentuan lokasi TEA yang dituju oleh setiap pengungsi pasca terjadi bencana agar tidak terjadi kelebihan kapasitas dan mempertimbangkan jarak tempuh evakuasi. Penentuan lokasi pengungsian dilakukan untuk tiga skenario yang dibentuk. Berdasarkan karakterisasi sistem evakuasi bencana tsunami yang dilakukan, selanjutnya dibentuk model matematis menggunakan Integer Linear Programming yang menentukan jumlah pengungsi mengungsi menuju suatu TEA dari setiap kelurahan terkena bencana. Model optimasi dibentuk dengan meminimasi total jarak tempuh pengungsi. Implementasi model dilakukan terhadap LINGO 13.0. Kemudian optimasi dilakukan dengan tiga skenario skala bencana.

Setiap kepala keluarga menetapkan lokasi TEA yang menjadi titik kumpul anggota keluarga pascabencana tsunami terjadi. Terdapat kerusakan jalan dan infrastruktur serta minimnya jumlah kendaran angkut, maka diperkirakan bahwa pengungsi melakukan evakuasi dengan berjalan kaki menuju TEA. Terdapat 104 kelurahan di Kota Padang, yang dikelompokkan ke dalam skenario kala bencana berdasarkan zona bahaya yang dimiliki kelurahan terkena bencana, yaitu pada skenario skala bencana besar terdapat 71 kelurahan, skenario skala sedang terdapat 58 kelurahan, dan skenario rendah terdapat 41 kelurahan. Gambar 2 menampilkan peta bahaya bencana tsunami Kota Padang dan sebaran lokasi TEA yang tersedia, terdapat 10 TEA. Data lokasi 10 lokasi TEA adalah TEA 1 (Bukit Lampu), TEA 2 (Kampus Universitas Putra Indonesia), TEA 3 (Kantor Camat Padang Selatan), TEA 4 (Komplek SMK Kartika), TEA 5 (PDAM Gunung Pangilun), TEA 6 (Kampus Poltekes Siteba), TEA 7 (Komplek TVRI by Pass), TEA 8 (Polsek Kuranji), TEA 9 (SPN Padang Besi), TEA 10 (Kantor Camat Pauh). 


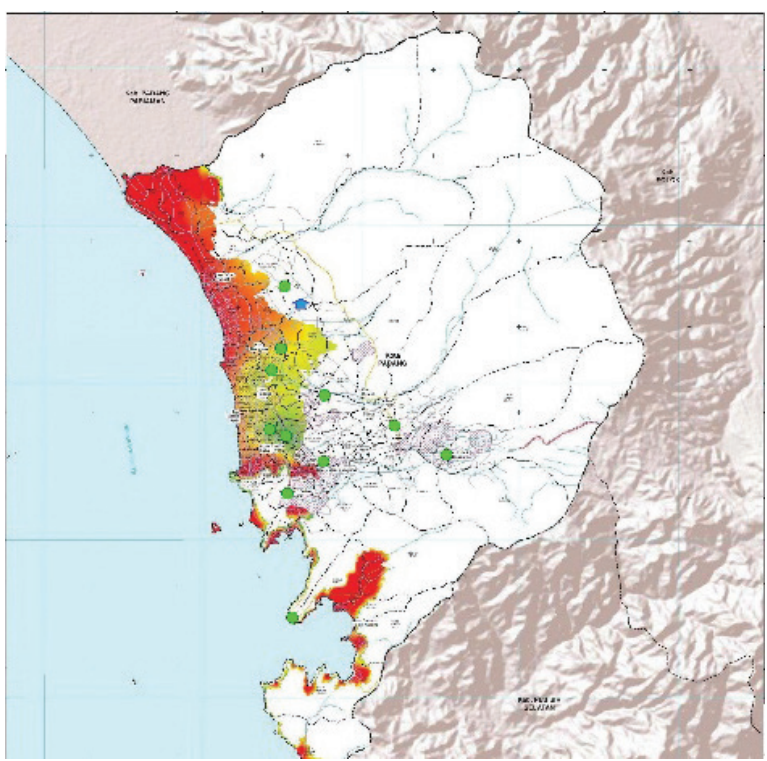

Lokasi TEA

Indeks zona bahava tsunami:

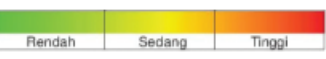

Gambar 2.

Peta Bahaya Tsunami Kota Padang dan sebaran lokasi TEA

(Sumber: Peta Oleh BNPB, 2013, Lokasi TEA di Plot oleh Penulis Berdasarkan

Data Lokasi dari BPBD Kota Padang)

Visualiasi sistem evakuasi yang dimodelkan gambar 3 di bawah ini.

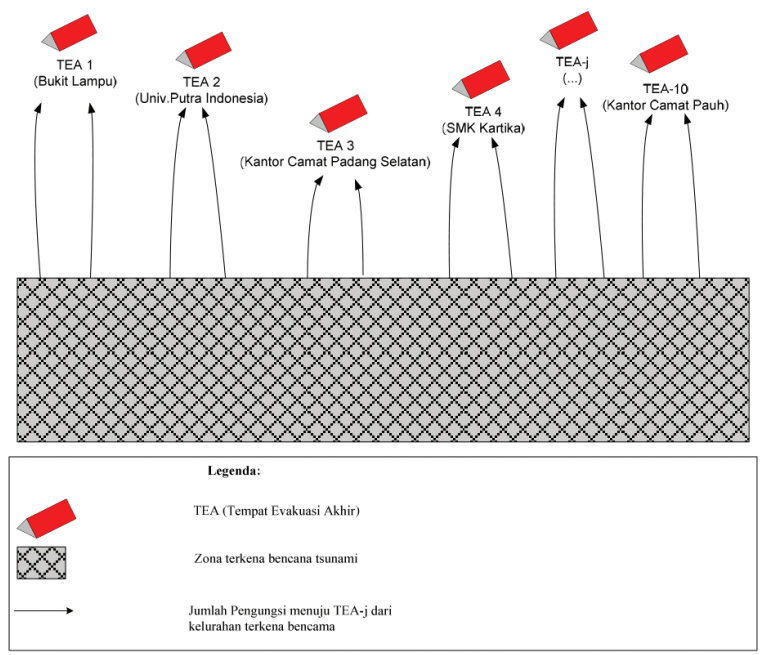

Gambar 3.

Visualisasi sistem evakuasi menuju TEA
Karakterisasi sistem terhadap sistem evakuasi yang dimodelkan terdapat pada Gambar 4.

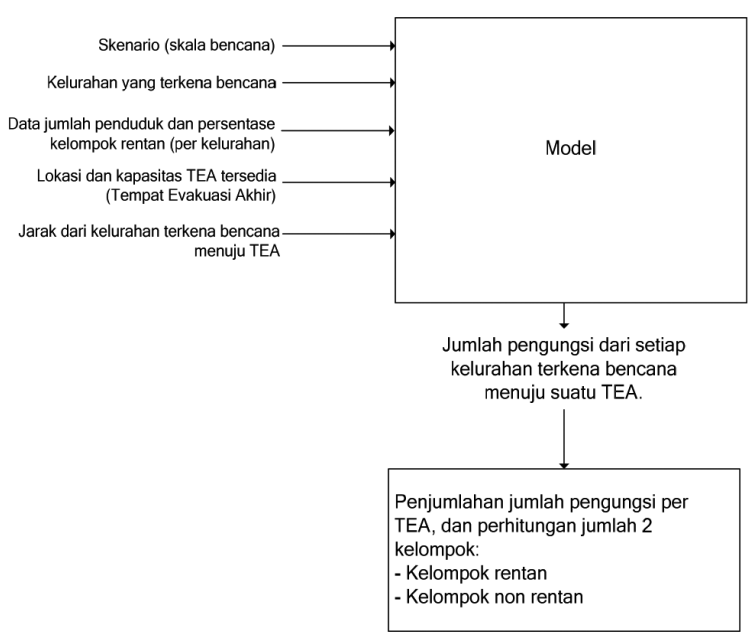

Gambar 4.

Karakterisasi sistem evakuasi menuju TEA

Formulasi model matematis dilakukan untuk menentukan lokasi mengungsi penduduk dari kelurahan terkena bencana menuju tempat evakuasi (TEA) sebagai berikut.

Variabel keputusan:

$m_{\mathrm{kj}}=$ Jumlah mengungsi dari kelurahan $k \in K$ mепији TEA $j \in J$

Fungsi tujuan:

$$
\text { Min total jarak tempuh }=\Sigma_{k \in K} d_{k j} \times m_{k j}
$$

Batasan:

$$
\begin{aligned}
& \sum_{k \in K} m_{k j} \leq k a p_{j} \\
& \sum_{j \in J} m_{k j} \geq N_{k}
\end{aligned}
$$

Keterangan:

$d k j=$ Jarak antar kelurahan $k \in K$ menuju TEA $j \in J$

$\operatorname{Kap}_{j}=$ Kapasaitas TEA $j \in J$

$N_{k}=$ Jumlah penduduk di kelurahan $k \in K$

Persamaan (2) menyatakan fungsi tujuan yaitu mengoptimasi jumlah pengungsi dari suatu kelurahan menuju suatu TEA yang dapat meminimasi total jarak tempuh. Persamaan (3) 
dan (4) merupakan batasan terhadap kapasitas setiap TEA dan seluruh penduduk yang melakukan pengungsian dari suatu kelurahan terkena bencana dipastikan harus mendapat tempat pengungsian di TEA. Hasil optimasi dari model ini adalah jumlah pengungsi dari suatu kelurahan ke suatu TEA.

Kemudian jumlah pengungsi tersebut dibagi menjadi kelompok nonrentan dan rentan. Kelompok rentan terdiri dari empat golongan, yaitu pengungsi wanita, pengungsi dengan usia ketergantungan, penduduk kurang mampu, dan disabilitas (BNPB,2013). Kelompok ini dinilai lebih rentan daripada kelompok masyarakat lain dengan asumsi bila terjadi bahaya, maka kelompok ini akan lebih mudah terkena dampaknya dikarenakan keterbatasan kemampuan menyelamatkan hidup (Hoesin di dalam Probosiwi dan Sudibyakto, 2013).

Perhitungan jumlah pengungsi per kelompok dilakukan dengan mengalikannya dengan persentase jumlah kelompok perkelurahan. Persentase jumlah kelompok diperoleh dari jumlah populasi kelompok (jiwa) dibagi total seluruh populasi pengungsi bencana tsunami di Kota Padang. Perhitungan jumlah pengungsi masing-masing kelompok setiap TEA adalah persamaan (4) dan (5) berikut.

Jumlah pengungsi kelompok rentan TEA $=$ $\sum_{k \in K}$ Pengungsi $_{k j} \times$ Persentase Kelompok rentan $_{k}$

Jumlah pengungsi kelompok non rentan TEA $=$ $\sum_{k \in K}$ Pengungsi $_{k j} \times$ Persentase Kelompok non rentan $_{k}$

\section{HASIL DAN PEMBAHASAN Optimasi Tiga Skenario Skala Bencana}

Optimasi dilakukan terhadap tiga skenario skala bencana dan menghasilkan untuk skenario bencana skala besar pada Tabel 1 .

Tabel 1.

Jumlah pengungsi per TEA pada skenario skala bencana tsunami besar.

\begin{tabular}{lcccccccccc}
\hline & TEA 1 & TEA 2 & TEA 3 & TEA 4 & TEA 5 & TEA 6 & TEA 7 & TEA 8 & TEA 9 & TEA 10 \\
\hline $\begin{array}{l}\text { Jumlah Pengungsi } \\
\text { Non Rentan Setiap }\end{array}$ & 2,089 & 11,047 & 4,863 & 6,787 & 13,861 & 3,803 & 25,598 & 18,099 & 13,385 & 53,371 \\
$\begin{array}{l}\text { TEA (jiwa) } \\
\text { Jumlah Pengungsi }\end{array}$ & 3,411 & 16,453 & 6,837 & 8,813 & 19,839 & 4,897 & 34,652 & 23,301 & 17,236 & 76,029 \\
$\begin{array}{l}\text { Rentan Setiap TEA } \\
\text { jiwa) }\end{array}$ & & & & & & & & & & \\
\hline $\begin{array}{l}\text { Jumlah pengungsi } \\
\text { Setiap TEA }\end{array}$ & 5,500 & 27,500 & 11,700 & 15,600 & 33,700 & 8,700 & 60,250 & 41,400 & 30,621 & 129,400 \\
\hline
\end{tabular}

Hasil optimasi untuk skenario bencana skala sedang diperoleh pada Tabel 2 berikut ini.

Tabel 2. Jumlah pengungsi per TEA pada skenario skala bencana tsunami sedang.

\begin{tabular}{|c|c|c|c|c|c|c|c|c|c|c|}
\hline & TEA 1 & TEA 2 & TEA 3 & TEA 4 & TEA 5 & TEA 6 & TEA 7 & TEA 8 & TEA 9 & TEA 10 \\
\hline $\begin{array}{l}\text { Jumlah Pengungsi } \\
\text { Non Rentan Setiap } \\
\text { TEA (jiwa) }\end{array}$ & 2,115 & 11,810 & 4,966 & 6,619 & 13,861 & 3,803 & & 17,452 & - & 48,893 \\
\hline $\begin{array}{l}\text { Jumlah Pengungsi } \\
\text { Rentan Setiap TEA } \\
\text { (jiwa) }\end{array}$ & 3,385 & 15,690 & 6,734 & 8,981 & 19,839 & 4,897 & 34,655 & 23,948 & - & 68,015 \\
\hline $\begin{array}{l}\text { Jumlah pengungsi } \\
\text { Setiap TEA }\end{array}$ & 5,500 & 27,500 & 11,700 & 15,600 & 33,700 & 8,700 & 60,250 & 41,400 & - & 116,908 \\
\hline
\end{tabular}


Hasil optimasi untuk skenario bencana skala rendah diperoleh pada Tabel 3 berikut ini.

Tabel 3. Jumlah pengungsi per TEA pada skenario skala bencana tsunami rendah.

\begin{tabular}{|c|c|c|c|c|c|c|c|c|c|c|}
\hline & TEA 1 & TEA 2 & TEA 3 & TEA 4 & TEA 5 & TEA 6 & TEA 7 & TEA 8 & TEA 9 & TEA 10 \\
\hline $\begin{array}{l}\text { Jumlah Pengungsi } \\
\text { Non Rentan Setiap } \\
\text { TEA (jiwa) }\end{array}$ & 2,115 & 11,781 & 5,263 & 6,355 & 15,387 & 2,999 & 25,294 & 16,591 & - & 1,949 \\
\hline $\begin{array}{l}\text { Jumlah Pengungsi } \\
\text { Rentan Setiap TEA } \\
\text { (jiwa) }\end{array}$ & 3,385 & 15,719 & 6,437 & 9,245 & 18,313 & 5,701 & 34,956 & 24,809 & - & 2,376 \\
\hline $\begin{array}{l}\text { Jumlah pengungsi } \\
\text { Setiap TEA }\end{array}$ & 5,500 & 27,500 & 11,700 & 15,600 & 33,700 & 8,700 & 60,250 & 41,400 & - & 4,325 \\
\hline
\end{tabular}

Berdasarkan optimasi model penentuan lokasi pengungsian dari kelurahan yang terkena bencana, diperoleh bahwa pada skala bencana tsunami besar diperlukan sepuluh TEA, sedangkan pada skala tsunami sedang dan rendah tidak digunakannya TEA 9 yaitu yang berlokasi di SPN Padang Besi.

\section{Analisis Karakteristik Populasi Pengungsi setiap TEA}

Pada skenario skala bencana besar, jumlah pengungsi terbesar terdapat pada TEA 10 yang berlokasi di Kantor Camat Pauh yaitu sejumlah 129.400 jiwa dan jumlah pengungsi kelompok rentan terbesar yaitu 76.029 jiwa. Pengungsi TEA 10 ini berasal dari 19 kelurahan, dengan jarak tempuh pengungsi terjauh berasal dari Kelurahan Parupuk Tabing, yaitu sejauh 14,5 kilometer. Kemudian diikuti oleh pengungsi berasal dari Air Tawar dan Ulak Karang. Selain itu pada lokasi TEA 9 juga terdapat pengungsi yang berasal dari titik asal pengungsian yang berasal dari Kelurahan Kampung Pondok dan Teluk Bayur memiliki jarak tempuh sejauh 13,4 kilometer.

Pada skenario skala bencana sedang, jumlah pengungsi terbesar terdapat pada TEA 10 yang berlokasi di Kantor Camat Pauh yaitu sejumlah 116.908 jiwa dan jumlah pengungsi kelompok rentan terbesar yaitu 68.015 jiwa. Pengungsi TEA 10 ini berasal dari 21 kelurahan, dengan jarak tempuh pengungsi terjauh berasal dari Kelurahan Koto Pulai, yaitu sejauh 17,2 kilometer, kemudian diikuti oleh Kelurahan Parupuk Tabing sejauh 14,5 kilometer.

Pada skenario skala bencana rendah, jumlah pengungsi terbesar terdapat pada
TEA 7 yang berlokasi di Komplek TVRI By Pass yaitu sejumlah 60.250 jiwa dan jumlah pengungsi kelompok rentan terbesar yaitu 34.956 jiwa. Pengungsi TEA 7 ini berasal dari 5 kelurahan, dengan jarak tempuh pengungsi terjauh berasal dari Kelurahan Koto Pulai, yaitu sejauh 17,2 kilometer, kemudian diikuti oleh Kelurahan Parupuk Tabing sejauh 14,5 kilometer. Pada skenario bencana rendah, jarak tempuh evakuasi terjauh yaitu pengungsi yang berasal dari Teluk Kabung Selatan menuju TEA 3, yaitu yang berlokasi di Kantor Camat Padang Selatan sebanyak 567 jiwa. Perbedaan karakteristik setiap populasi pengungsi di setiap TEA perlu dipahami untuk agar dapat membantu perencanaan pada fase tanggap darurat yang dilakukan pascabencana.

Berdasarkan analisis populasi pengungsi setiap TEA, diperoleh sejumlah TEA yang memiliki populasi pengungsi terbesar di antara TEA lainnya, yaitu pada skala bencana besar dan skala bencana sedang adalah pada TEA 10, sedangkan pada skala bencana rendah terdapat populasi pengungsi terbesar terdapat pada TEA 7. Berdasarkan populasi kelompok rentan terbesar. TEA yang memiliki populasi kelompok rentan yang tinggi pada skenario skala bencana besar terdapat pada TEA 10, dan skala bencana sedang terdapat di TEA 10 sedangkan pada skala rendah populasi pengungsi rentan berada pada TEA 7. Selain itu diketahui sejumlah pengungsi memiliki jarak tempuh yang besar dibandingkan jarak tempuh pengungsi lainnya. Jarak tempuh evakuasi pada suatu kelurahan terkena bencana menuju TEA yang berjarak tempuh jauh memungkinkan untuk dilakukan persediaan transportasi kendaraan dalam melakukan evakuasi. 


\section{Analisis Perubahan Jumlah Penduduk terhadap Kebutuhan TEA}

Analisis dilakukan terhadap perubahan variabel jumlah penduduk yang berada di kelurahan terkena bencana. Berdasarkan peraturan yang ditetapkan oleh BNPB, BPBD Kota Padang akan memperbaharui rencana kontingensi setiap tiga tahun yaitu penyusunan rencana dalam menghadapi bencana tsunami jika suatu saat terjadi. Rencana kontingensi yang dibentuk terakhir disusun untuk tahun 2013-2016, sehingga perlu penyusunan untuk tahun 2016-2019. Maka akan dilakukan analisis terhadap perubahan jumlah penduduk pada model optimasi ini. Dengan menggunakan data laju pertumbuhan penduduk pertahun yang ada di Kota Padang adalah senilai 1,44\% (BPS, 2016), maka diperoleh perhitungan jumlah penduduk pada tahun 2019, perhitungan dilakukan untuk kelurahan terkena bencana pada skala besar, sedang, dan rendah. Perubahan parameter jumlah penduduk pada tahun 2019 terhadap kebutuhan jumlah TEA dan jumlah pengungsi setiap TEA terdapat pada Tabel 4 berikut.

Tabel 4. Rekapitulasi hasil analisis perubahan jumlah penduduk tahun 2019 terhadap model evakuasi menuju TEA.

\begin{tabular}{|c|c|c|c|c|c|c|c|c|c|c|}
\hline & TEA 1 & TEA 2 & TEA 3 & TEA 4 & TEA 5 & TEA 6 & TEA 7 & TEA 8 & TEA 9 & TEA 10 \\
\hline \multicolumn{11}{|c|}{ SKALA BENCANA BESAR } \\
\hline \multicolumn{11}{|l|}{ No Solution } \\
\hline \multicolumn{11}{|c|}{ SKALA BENCANA SEDANG } \\
\hline $\begin{array}{l}\text { JUMLAH } \\
\text { PENGUNGSI } \\
\text { SETIAP TEA }\end{array}$ & 5500 & 27500 & 11700 & 15600 & 33700 & 8700 & 60250 & 41400 & 34538 & 129400 \\
\hline KAPASITAS TEA & 5500 & 27500 & 11700 & 15600 & 33700 & 8700 & 60250 & 41400 & 40950 & 129400 \\
\hline $\begin{array}{l}\text { SISA KAPASITAS } \\
\text { YANG TIDAK } \\
\text { TERGUNAKAN }\end{array}$ & 0 & 0 & 0 & 0 & 0 & 0 & 0 & 0 & 6412 & 0 \\
\hline \multicolumn{11}{|c|}{ SKALA BENCANA RENDAH } \\
\hline $\begin{array}{l}\text { JUMLAH } \\
\text { PENGUNGSI } \\
\text { SETIAP TEA }\end{array}$ & 5500 & 27500 & 11700 & 15600 & 33700 & 8700 & 60250 & 41400 & 0 & 34876 \\
\hline KAPASITAS TEA & 5500 & 27500 & 11700 & 15600 & 33700 & 8700 & 60250 & 41400 & 40950 & 129400 \\
\hline $\begin{array}{l}\text { SISA KAPASITAS } \\
\text { YANG TIDAK } \\
\text { TERGUNAKAN }\end{array}$ & 0 & 0 & 0 & 0 & 0 & 0 & 0 & 0 & 40950 & 94524 \\
\hline
\end{tabular}

Hasil analisis perubahan parameter variabel jumlah penduduk diketahui bahwa untuk skala bencana besar, tidak terdapat solusi yang feasible karena jumlah pengungsi keseluruhan telah melebihi kapasitas TEA yang tersedia. Pada skala bencana sedang memperoleh hasil bahwa dibutuhkan kesepuluh TEA yang tersedia, tetapi masih menyisakan kapasitas tidak terpakai pada TEA 9 (SPN Padang Besi) dengan jumlah 6.412 jiwa. Sedangkan pada skala bencana rendah memperoleh hasil bahwa dibutuhkan sembilan TEA yang tersedia, dengan tidak menggunakan TEA 9 (SPN Padang Besi) serta masih menyisakan kapasitas tidak terpakai pada TEA 10 (Kantor Camat Pauh) dengan jumlah 94.524 jiwa.

\section{SIMPULAN}

Berdasarkan optimasi lokasi TEA, diperlukan sepuluh TEA untuk bencana tsunami skala besar. Sedangkan pada skala bahaya tsunami sedang dan rendah tidak menggunakan TEA 9 yang berlokasi di SPN Padang Besi.

Berdasarkan hasil optimasi, jumlah pengungsi keseluruhan dan jumlah kelompok rentan terbesar pada skenario skala besar 
berada pada TEA 10 yang berasal dari 19 kelurahan. Kemudian pada skenario skala sedang terdapat pada TEA 10 yang berasal dari 21 kelurahan, sedangkan pada skenario skala kecil terdapat pada TEA 7 yang berasal dari 5 kelurahan.

\section{DAFTAR PUSTAKA}

Ashar,F., Amaratunga,D., dan Haigh,R., 2014, The Analysis of Tsunami Vertical Shelter in Padang City, Procedia Economics and Finance 18: 916 - 923.

BNPB, 2013, Rencana Kontingensi Menghadapi Bencana Tsunami Kota Padang, Pemerintah Kota Padang.

BNPB, 2014, DokumenJalur Evakuasi Bencana Tsunami Kota Padang,tahun 20142019 (Perencanaan dan Rekomendasi), Pemerintah Kota Padang.

BPS, 2016, Kota Padang dalam Angka Tahun 2016.

Chinnek,J.W., 2001, Practical Optimization: a Gentle Introduction, $h t t p: / / w w w . s c e$. carleton.ca/faculty/chinneck/po.html.
Masruroh,N.A., 2014, Resensi Operations Research Strategi Efisiensi Bermula dari Perang, Jurnal Teknosains, Vol 3, No.2, Juni 2014:158-162.

McCloskey,J., Antonioli,A., Piatanesi,A., Sieh,K., $\quad$ Steacy,S., Nalbant,S., Cocco,M., Giunchi,C., Huang,J.D., dan Dunlop,P., 2008, Tsunami Threat in The Indian Ocean from a Future Megathrust Earthquake West of Sumatera, Earth and Planetary Science Letters 265: 61-81.

Probosiwi,R., dan Sudibyakto, 2013, Manajemen Risiko Tsunami untuk Penataan Ruang di Pesisir Perkotaan Pacitan Jawa Timur, Jurnal Teknosains, Vol 2, No.2, 22 Juni 2013:71-158.

Purbani,D., Ardiansyah., Dewi.L.C., Prihantono.J., dan Bramawanto.R, 2014, Penentuan Tempat Evakuasi Sementara(Tes) Dan TempatEvakuasi Akhir (Tea) Untuk Gempa Bumi Dan Tsunami Dengan Pendekatan Sistem Informasi Geografis, Kota Pariaman Propinsi Sumatera Barat, J. Segara Vol. 10 No. 1 Agustus 2014: 1-16 